\title{
It's (Red) Hot Outside! The Aesthetics of Climate Change Activists Extinction Rebellion
}

\author{
Gretchen Coombs \\ RMIT University, Australia \\ gretchen.coombs@rmit.edu.au
}

\begin{abstract}
From 20I I's Occupy movements to the Umbrella Movement Hong Kong to the recent Climate March in September 2019, typified by Extinction Rebellion's performative acts of resistance, there's been an exponential increase in protests around the world. People move together en masse to challenge economic inequality and political ineptitude; they demand racial justice and action against climate change and Indigenous land rights. Ideally, protests and forms of direct action generate new ideas where the use of bodies in space become conduits to spark debate, bring awareness, with the hope to change the discourse about urgent issues. The visual power of many bodies speaking both to each other and to a larger public offers a space everyone can safely participate in the social imaginary. This paper considers Extinction Rebellion's graphic and performative aesthetics.
\end{abstract}

Keywords: Extinction Rebellion, aesthetics, performative

To cite this article:

Coombs, G. (2020) It's (Red) Hot Outside! The Aesthetics of Climate Change Activists Extinction Rebellion, The Journal of Public Space, 5(4), I23-I36, DOI I0.3289I/jps.v5i4.I407

This article has been double blind peer reviewed and accepted for publication in The Journal of Public Space. 


\section{Introduction}

From 20I I's Occupy movements to the Umbrella Movement Hong Kong to the recent Climate March in September 2019, typified by Extinction Rebellion's performative acts of resistance, there's been an exponential increase in protests around the world. People move together en masse to challenge economic inequality and political ineptitude; they demand racial justice and action against climate change and Indigenous land rights. Ideally, protests and forms of direct action generate new ideas where the use of bodies in space become conduits to spark debate, bring awareness, with the hope to change the discourse about urgent issues. The visual power of many bodies speaking both to each other and to a larger public offers a space everyone can safely participate in the social imaginary.

Black masks, red robes, pink pussy hats, and umbrellas of every colour connect bodies as they occupy public spaces-flowing through streets, crowding intersections, and populating parks-forming new publics who confront normalized social structures, power relations, or forms of authority. On display are signs, slogans, selfies, symbols, humour, graffiti, sometimes violent and sometimes kind gestures, and even libraries. These traces comprise the textual, material, affective, and performative residue of cultural participation that turn the ordinary into something unexpected as choreographed bodies move through and occupy urban public spaces. Their temporality gets extended through social media. The colours, materials, disruptions and corporeality constitute the aesthetics of protest, which "are performative and communicative, constituting a movement through the performance of politics" (McGarry et al. 2020, 15); forming and enacting essential pillars of democracy. The semiotics of aesthetics contribute to the increased visibility of global protest, and for Nicholas Mirzoeff, they are part of "visual culture to create self-images, new ways to see and be seen, and new ways to see the world' $(2015,297)$.

Protest, according to Judith Butler, challenges "the inchoate and powerful dimensions of reigning notions of the political" $(2015,9)$, and stems from discontent; actions arise from perceived exclusions and inclusions, injustices and inequalities in society or against political power. The history of protest can be traced back to well before the American and French Revolutions to the $20^{\text {th }}$ century's postcolonial struggles, civil rights and women's rights, to the current wave of protest for racial justice and Indigenous sovereignty and to upend white supremacy. As Stephen Duncombe points out, "In the English language the words "protest" and "demonstration" are often used interchangeably; it is a revealing slippage. For people use protest not only to act against power in the here and now, but also to demonstrate a different model of power, and an ideal of the world, they would like to bring into being in the future (cited in Rogger, et al., 2018, 94). In this context, protest extends beyond vocalization and blockades with demands for action through demonstration, to performance, sound, image, and sign. These forms of direct action, disruption, and protest may offer social tipping points for urgent issues, but increasingly protests have become very mediagenic. ' To what extent do protests in public space become just a visual enactment of democracy, a spectacle that is tolerated because voice, opinion, and dissent are contained yet structurally, nothing changes? How can the aesthetics of protect and direct action disrupt our sense

\footnotetext{
${ }^{1}$ These terms are distinct, I understand, but for purposes of this paper, I will speak about protest as well as disruption, keeping in mind they are acted and interpreted across different social and political registers.
} 
of what is possible and what can be done and seen in public spaces? For McGarry et al., "When people assemble in a public space they challenge the idea that the state alone has the authority to determine how it is to be used, whether for ritualistic pageantry or as an expression of state power...the public square acts as a theatre where the individual and collective identities of protestors are performed, as it communicates ideas of democracy, including specific demands and grievances" $(2020,24)$. McGarry et al state "performance of protest not only questions and subverts ideas of where politics is done, but constitutes a rupture to the existing political order by its enactment" $(2020,26)$.

Performances of disruption, creative forms of direct action, non-violent civil disobedience are art practices that challenge prevailing structures, intervene to reimagine how we learn about issues, how we might respond, but also what can be changed. And importantly, for these artists and activists, the question becomes, how can you embody and then express your cause? With bodies central to these actions, how can we see them as part of the aesthetic dimension of protest? What forms of protest galvanize our imagination and how are visual codes and performances - the aestheticsused to subvert or support power, and importantly inculcate publics into the cause? There are many types of protests and there are many ways to consider aestheticsvisual signs, materials, and symbols are one way. The other is the more performative protest, what we might call a social art practice that responds/resists/and embodies a particular issue, increasing visibility and amplifying the issues at hand; in other words, doing and enacting politics differently.

James Aulich describes the aesthetics of protest as Janus-faced:

There is the aesthetic form of the protest in its present: the crowd, banners, posters, speeches, chants, songs, and actions of protestors and police. Then there are the aesthetics of the trace of the demonstrations in analogue and digital media, in the imagination and memory, and in their systems of distribution and wider cultural contexts. The 'phenomenon' and its 'image' are in an entangled relationship, each feeding the other to embody a collective act of protest (in McGarry et al., 2020, 272).

Both are critical interventions into dominant representations and forms of political visibility; it is critical to understand how we might understand how this aesthetics and their a/effect on witnessing and participating publics, as well as the activists themselves. This article considers the aesthetics of climate change activists Extinction Rebellion whose communication design features vivid graphics and branding, and whose performative protests have blocked traffic, enraged onlookers, and given a new sense the power of movement, corporeality, and the colour red. ${ }^{2}$ I am interested in how the performative aesthetics of Extinction Rebellion intervene in more common articulation of protest and aesthetics and how they bring awareness to climate change.

The French philosopher Jacques Rancière (2004) defines aesthetics as a "specific regime for identifying and reflecting on the arts: a mode of articulation between ways of doing

\footnotetext{
${ }^{2}$ I am broadly referring to socially engaged art practices, or creative forms of activism, because I believe in their potential. That being said, the urgency of the times in which we live necessitates direct action, and I acknowledge the social movements big and small who have been working in this space for decades.
} 
and making, their corresponding forms of visibility, and possible ways of thinking about their relationship. In other words, aesthetics (specifically the interdisciplinarity of contemporary art practices and creative forms of activism) is being ever more called upon to provide both insight into politics itself and the stimuli for social change. Rancière uses the "aesthetic regime" (2006) and "distribution of the sensible" to speak to the relationship between art and politics in terms of relations between visible/invisible, participant/observer, and consensus/ dissensus. He looks to art in relation to politics because he recognizes that politics is ultimately a platform for determining social realities, and this is essentially manifested as and by aesthetic practices. Art and the aesthetic experience are already inherently political for Rancière, and "the political" needn't be isolated into content driven art forms nor political dissent into direct action and street demonstrations. In this reconfiguration aesthetics becomes much more than beauty, judgement, and taste but is tied up with politics and the ability to shift perceptions on the world through art work or performative actions (Coombs 2014). Extending the traditional Kantian aesthetic of detached judgement to consider these works not only for their aesthetic forms - materials, form, line, patterns and repetition reveals how those aesthetic forms disrupt the ways in which we relate to the world and "conceiving aesthetics as a practice, a resource, a choice with instrumental and expressive components... its materiality and visual dimensions, its silence, its vocalization, and its rhythm" (McGarry et al. 2020, I7).

\section{Extinction Rebellion}

Rebel for life. For the planet. For our children's children's futures.

Visual signifiers of climate change protest vary from group to group, yet Extinction Rebellion (XR) defined their own unique language through the use of familiar cultural signs and symbols, sometimes appropriated or reinterpreted, and which are easily recognizable to the public. These visual and material forms connect bodies and ideas as they flow through streets, crowded intersections, and populate parks.

$\mathrm{XR}$ is an international movement that promotes non-violent civil disobedience and direct action in an effort to compel governments to take notice and for the public who encounters to take urgent action in climate change. They have three demands: TELL THE TRUTH- Government must tell the truth by declaring a climate and ecological emergency, working with other institutions to communicate the urgency for change. ACT NOW-Government must act now to halt biodiversity loss and reduce greenhouse gas emissions to net zero by 2025. BEYOND POLITICS- Government must create and be led by the decisions of a Citizens' Assembly on climate and ecological justice (Extinction Rebellion, nd). Included are artists, activists, scientists, academics, all unified under a certain aesthetic; leaflets, posters, and other visual communication are downloadable for free from their XR's website. Since 2018 the decentralized groups have been active in the UK and have since spread worldwide to 69 countries with II 34 groups. XR became quite visible during 2019's bush fires in Australia, demanding urgent action as the continent burned. 


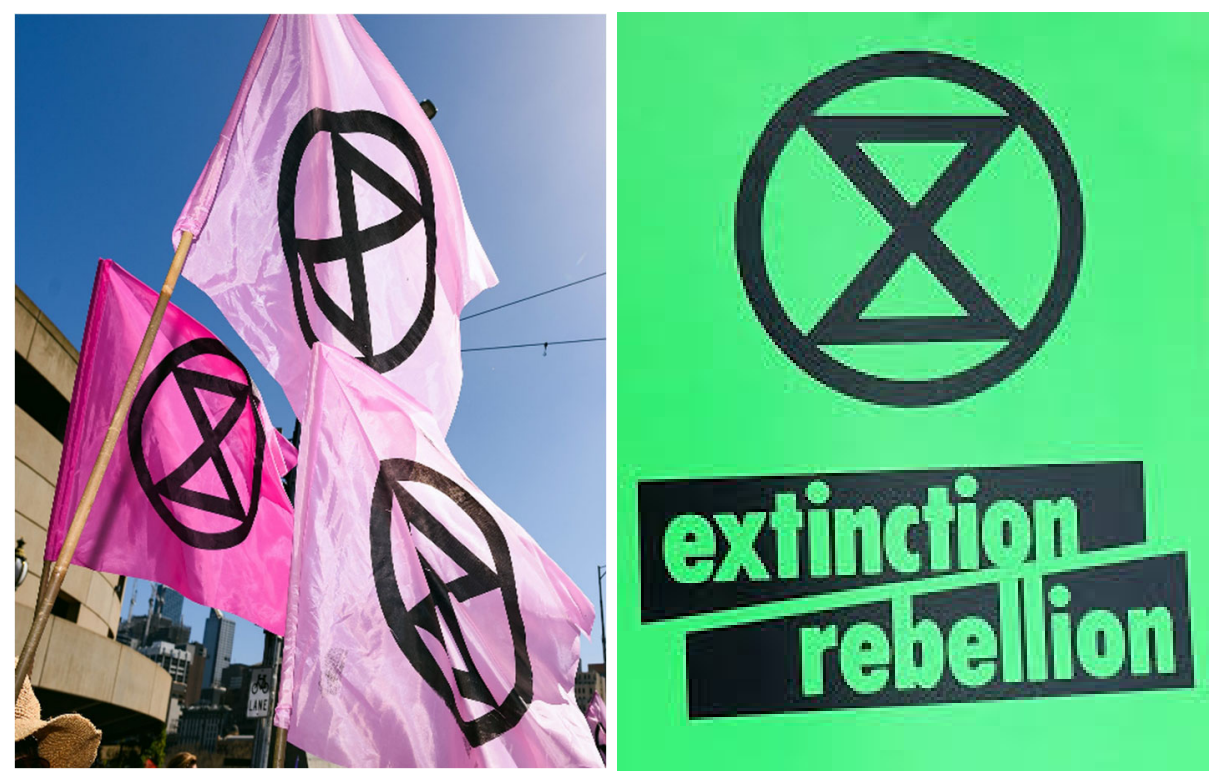

Figure Ia, b. Examples of XR's logo

What is interesting about XR's strategy is that they anticipated the mediagenic component of protest with consistent visual communication strategies. In other words, they are on brand. Their visual language is bright with a defined palette of colors, a snappy font and woodcut illustrations of skulls and nature made by collaborator Miles Flynn. The "millennial pink" greens and slightly crooked font are consistent and straight forward borrowing from the playbook of the Situationist International's 1968 posters where design played a pivotal role in the French general strike that in May 1968 and which nearly toppled the French government. Sl's posters not only conveyed the important message that things could be different, but, importantly, getting people to read them with recognition. According to Clive Russell, who designed the font and worked with XR founder Roger Hallam, it was important not to reproduce a hippy or punk aesthetic, but to be new and fresh, and to welcome others in. They inverted the familiar hippy aesthetic common to environmental movements from the 1970s onwards. Such visual representations are crucial to both social movements and protesters who wish to communicate their identities and their messages to wider audiences and to the general public. Images do not merely supplement news but, as Machin and Polzer (20I5, I) argue, they "form part of the ideas about the world, concepts and attitudes that are communicated." XR's logo has become recognizable on placards, leaflets, and recently as it projected onto buildings. Created by UK street artist ESP, the stylized hourglass in a circle denotes that time is running out to act on climate crisis (Morris 2019). "Time's Up, Act Now" and "Tell the Truth" framed the hourglass logo as a projection onto the Tate Modern's gallery's chimney in 2019.

$\mathrm{XR}$ are not the first but they might be most visible climate change activists right now. They take advantage of their strong visual communication and circulate their image and message through diverse media outlets, and transmit them in new ways, on buildings for example. Arguably, their campaign has been successful because their symbols and cultural narratives simplify complex ideas and then relate them to familiar forms of visual culture. An engaging and provocative presentation of ideas becomes crucial for 
persuading individuals to internalize those ideas and then act upon them. By tapping into the power of media their urgency can circulate broadly, and contribute to the process by which the values they are advocating become normative and legitimized.

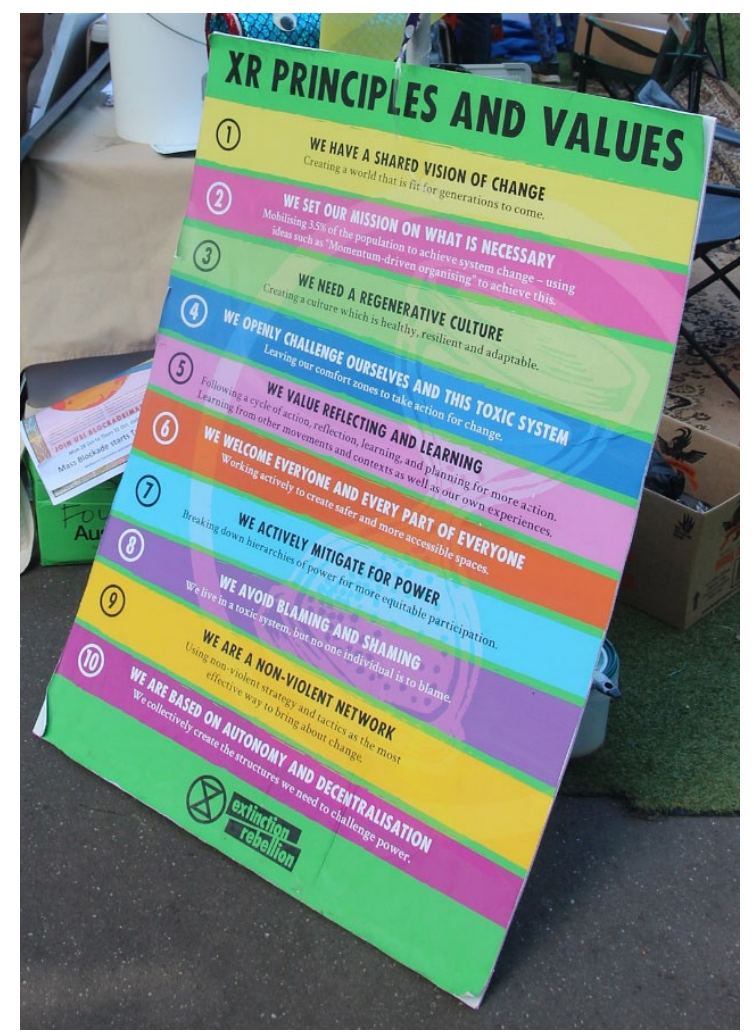

Figure 2. XR's Principles and Values, Melbourne 2019.

Photo credit: Takver, Wikimedia Commons

One of the most arresting visuals of XR are ghostly-white figures cloaked in scarlet-red, drifting gracefully down roads, through lines of police, weaving through crowds of demonstrators, and walking on beaches into the sea. From above they look like arteries of blood pumping, contained and with a mission to circulate. Their look is unforgettable. The Red Brigade, also known as the Red Rebels, demonstrate the calm, restrained, and silent. These theatrical elements of protest and measured delivery of information augment XR's visual communication by through a corporeal experience. Inserting these performative actions into public space raises visibility to be sure, but it also allows the public to witness protest on a different register. That is, they are received as a performance troupe before they are seen as protestors. As such, the public art component of their work opens the imagination to new ways of experiencing protest. The Red Brigade grew out of a Bristol street performance troupe, the Invisible Circus (Heardman 2019). The resemble human statues, forming a tableaux silent witnesses, standing to take notice, providing a unifying message. They appear gentle, arms outstretched and often interlocked. The group say the red signifies blood that we all share across species. The white faces also create unity and allow for expressions to be more pointed. Their goal is to evoke empathy through movement and expression, much 
like the tradition of Butoh dancers. These dramatic flares of red resemble interlocking chains and demonstrate the interconnectivity of all beings and the measured steps needed to address climate change, and each body carries a story, which allows a certain vulnerability. Their slowness and deliberation is precisely the cutting intervention needed. Slow down. Slow down. Learn. Subvert compassion fatigue or even empathy fatigue to give way to the accessible, meaningful, new visions that art can provide. They are thoroughly planned, organized, and choreographed with military precision. ${ }^{3}$ Founder Doug Francisco reflects on the group's goal: "We wanted people to almost empathically feel and understand our message, which is the power of art" (cited in Heardman 2019). During protests multiple crowds form: media, onlookers, participants, allies, police, and so to confront the now familiar signs and banners, marches and soap boxes. Anthropologist Michael Taussig (2012) acutely describes how many protests engender fatigue, and that often-times the protesters' tactics really offer nothing new, so a group in red robes might puncture this fatigue. These forms of disruption don't just point to an issue like you see in many protests but the tactics work to shift the issue through this type of embodiment.

The crimson robes and choreographed movements connect the performers and publics bring attention to their cause. They are immersive experiences in which visual patterns and communication form a background to the participants' bodies, evoking a sense of confinement. By its publicness, whether on the street as a part of or as a spectator, we enter into a relation as we participate and bear witness. This materialization, these counterpublics form around a shared purpose (Warner 2002), and as Butler states, "If the people are constituted through a complex interplay of performance, image, acoustics, and all the various technologies engaged in those productions, then "media" is not just reporting who the people claim to be, but media has entered into the very definition of the people" $(2015,20)$. Protest plays out as a phenomenon and reaches into multiple performative fields and received through multiple registers (social media, mainstream media, on the ground reportage, etc.) and through movement, gesture, and bearing witness.

\footnotetext{
${ }^{3}$ Other notable performative protests for climate change include Laresa Kosloff's Radical Acts (2020), a short film featuring the humorous tactics of climate change scientist; and Culture Declares Emergency procession in London 2019. Perhaps most significantly is the work of Liberate Tate, and as a contrast to XR's aesthetics in public space, Liberate Tate employs similar strategies in a museum space (foyers and galleries) most notably in the Tate's foyer for Human Cost (20II) when a performer and charcoal, laid down while two people poured what was perceived to be oil all over the performer (it was sunflower oil and charcoal). Visitors stopped, took note, moved on, and some ignored the performer all together. What expectations or organizing principles are in a gallery or a museum? There's a certain code of behavior, even upon entering the space. Some of these social codes include being quiet, contemplative, or to take a certain path to follow, lots of reading, contemplating, and quiet meditation. Yet, what happens if you confront a non-sanctioned somewhat disruptive performance as you enter? Would you think it's part of the gallery or museum programming? Because those codes are already in place, you might watch, listen, and interact because you are in the site already. Liberate Tate wants to take power away from oil companies. This performance took place on the first anniversary of the start of the BP Gulf of Mexico disaster. It lasted for $\mathbf{8 7}$ minutes, one for every day of the spill. LT's has as its focus the body in space (that can be used as a tool of resistance) and non-violent direct action. Their actions have weakened normalized institutional structures by bringing problems into view and charting a new way to question and act within the hallowed halls of a museum.
} 


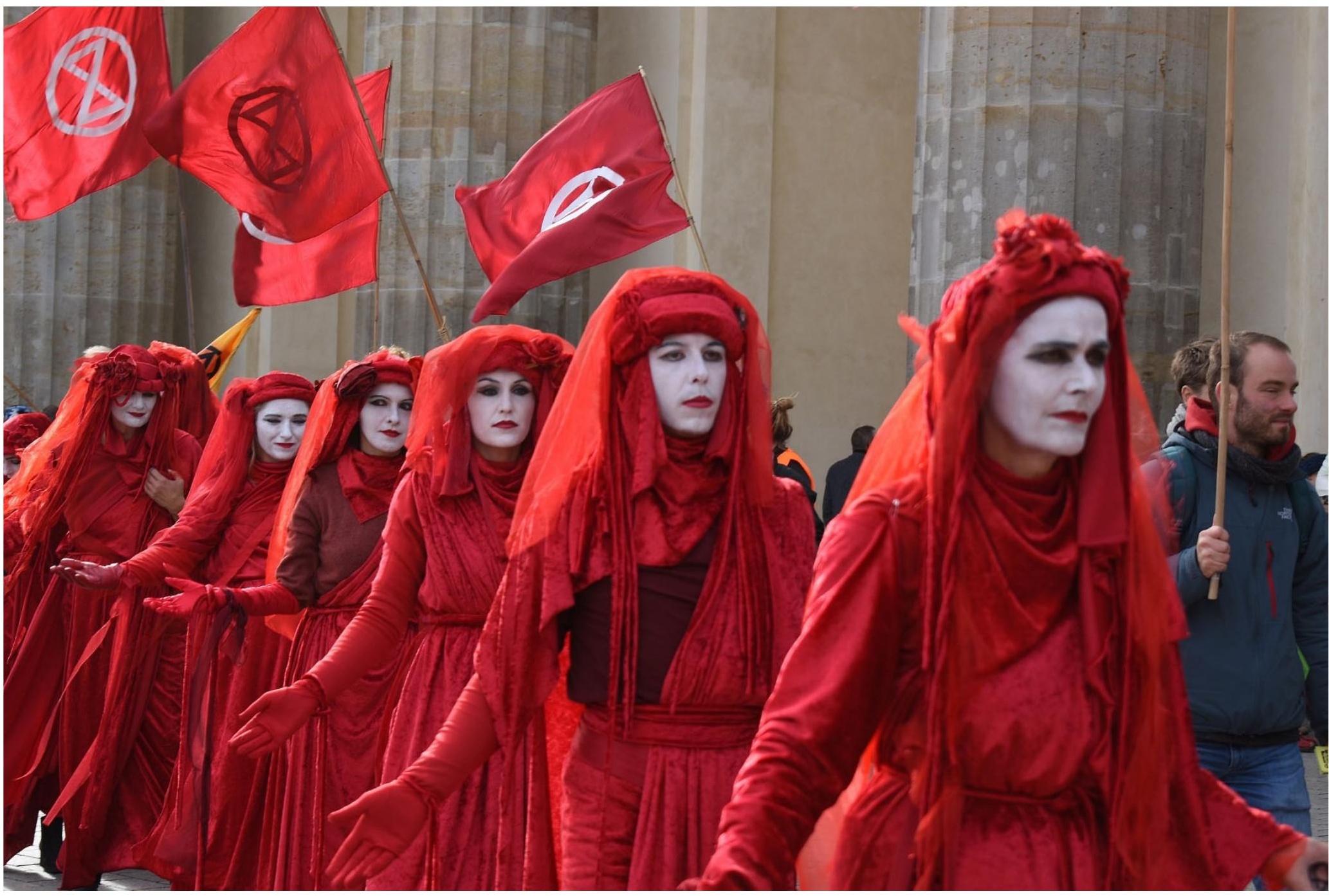

Figure 3. Red Brigade: Extinction Rebellion, Berlin II.10.2019 Photo credit: Benno Kirsch. Wikimedia Commons

$\mathrm{XR}$ brands themselves successfully and have used their visual communication becoming recognizable by coordinating their visual communication, what brand names do as part of a capitalist toolkit to sell consumers their wares, and increasingly their ideas. ${ }^{4}$ Yet, as Morris (2019) points out, XR's branding tactics and "in your face" public disruptions connect with a consumer culture interest in sustainable capitalism where instead of ideas being sold, the message and spectacle are disturbed. No matter what this might mean in terms of capitalist appropriation or co-optations, it is critical to cut through spectacle with spectacle, and arguably works like EX do so.

$\mathrm{XR}$ have also been called out for their "urgency" which eclipses the long-time experiences inflicted on Indigenous community through settler colonialism, with many communities worldwide on the for front of climate change. Activists working in the

\footnotetext{
${ }^{4}$ As a precedent to such fashion branding early in the 20th century, see the Suffragettes's who used purple green and white to signify loyalty and dignity, white for purity, and green for hope. Members were encouraged to wear the colours "as a duty and a privilege." See for example,

https://www.theguardian.com/fashion/2015/oct/08/suffragette-style-movement-embraced-fashion-branding
} 
space have suggested the group's myopic sense of urgency needs to delve more into the racialized history and violence and those who have been advocating for environmental justice. He states, such measure needs "bringing past emergencies into proximity with present ones, connecting them through their complex disjunctions and equally their continuities" (Demos, 2020, 19).

There are limitations and even dangers of relying on highly aesthetic visuals and performance. The risks members of XR take for their creative acts of civil disobedience are a privilege. The group's emphasis on disruption, with tactics asking protesters to allow themselves to be arrested, excludes the groups that are more likely to be mistreated by police, in particular, people of colour. Despite their goal to disrupt and have people take notice, business owners get affected by the road closures, people struggle to get to work or get children to school, taxi drivers' livelihoods are affected, and so on. Those who are caught in the "inconvenience" are potentially alienated, not to mention the increased emissions of idling cars makes an easy target for those irritated by the group (for example, Australia's conservative Courier Mail has been very critical of the group). T. J. Demos' outlines a more sustainable way forward:

"intersectionalist ecology demands a corresponding activism of alliance building across identities of difference, starting from a disidentification from oppressive dominant hierarchical formations of white supremacy, colour-blind liberalism, and speciesist anthropocentrism" (2020, 20).

These limitations aren't limited to XR's tactics or aesthetics but to most forms of activism in public spaces or to highly mediagenic visual communication. Yet, it remains important to ask if these forms of disruption engender agency amongst the public and/or audiences, or in the case of Extinction Rebellion offer enough of a spectacle to bring attention to these issues brought on by the climate crisis. Do XR's forms of protest galvanize our imagination by employing visual codes and performance to subvert or support power? Is it art, is it activism, is it a spectacle? Yes, probably all three, but definitions are less important than what they can do in the world and to those who encounter them. To better consider these questions, I will return to Jacques Rancière's configuration of art and politics, phenomenology and "intra-action" to interpret and understand their function in the world and how they produce alternative subjectivities.

\section{The Body and The Encounter}

How do these aesthetic strategies in the form of public art performance produce political subjectivities and reorient relationships amongst participants, with each other, and in response to social and political concerns?

$X R$ 's performances take conceptual frameworks to the streets, creating performative displays that support and help expand the cultures of local communities in urban life. These temporary occupations of space, conscious of people and the relations they engender points to a "condition [that] situates us in an enunciative and performative relationship to the world (and to art), where meanings take place, in what theorist and curator Irit Rugoff calls "the where of now," by making a form of location through inhabiting temporal duration" (cited in Douglas 20II, 57). Indeed, once we consider the body as the site of our encounter with the world, enmeshed in multiple relations with myriad bodies in varied contexts, it follows logically to think of corporeality as a vital nexus of 
physical struggle and virtual communication" (Kraidy cited in Peeren et al., 2017, I20).

XR's performance actions are relational acts. They require recognition, witness, and response from publics. They visually mediate self, other, and the world, producing a "social aesthetic as the embedded and embodied process of meaning making which, by acknowledging the physical/corporeal boundaries and qualities of the inhabited world, also allows imagination to travel across other spaces and times. aesthetics alerts us to the creativity involved in routine social practices" (Olcese and Savage 2015, 724). Their actions become a mode of experiencing the world itself, a phenomenological encounter. In public space Kraidy notes "creative insurgency cannot be understood through a mind-body dualism, but rather constitutes an embodied joining of the mental and the physical, the symbolic, and the material" (Kraidy 2016). Seeing these disruptions from a phenomenological perspective, focused on the body as the primary interface between individual and world-an essential instrument of perception and the locus of lived experience - makes significant contributions to our understanding of embodied contestation. This "being in the world" (Merleau-Ponty 2012, 84 cited in Kraidy). For Kraidy this means: "being-in-the-world is tantamount to being engaged- in the sense of involved but also enmeshed - in the world" (Kraidy in Peeren et al., 2017, 122). We witness how performance reimagines what can happen or be felt in public spaces and become a focal point around which social awareness and proximity increase, and reposition individuals and newly formed publics towards aspects of cultural life often overlooked in our crowded visual sphere.

Feminist theorist Karen Barad describes this as "intra-action," (2007) as a way to expand a phenomenological encounter and offer another facet to Rancère's dissensus and distribution of the sensible, discussed below in more detail. While these may seem like different epistimo-ontological positions, I believe it's illustrative to consider them together all as they help articulate how aesthetic encounters can shift or create new political subjectivities based on the interactions between the material, the affective, and the experiential in public spaces - as performers, allies, or passer-bye. James Aulich cites Barad's "intra-action" to understand how protests and their audiences or publics might be affected and is worth quoting at length:

The action of the protestor, the greater cause and its mediation are not separately determined. Their relations or intra-action determine their boundaries and properties, they are not there to be found as if they were preexistent, the 'object' and the 'agency of observation' are inseparable" Citing Barad is useful here, as it reinforces the relational ontology of moving through, observing, or protesting in public spaces. The inextricable connects between body and performance. Entities, agencies and events 'are only distinct in a relational, not an absolute sense, that is, agencies are only distinct in relation to their mutual entanglement; they don't exist as individual elements' (Barad 2010, 267, note I cited in Aulich 273).

Rancière's "distribution of the sensible" (2006) frames how we perceive and that which regulates the perception of our social roles and our subsequent affective response. Challenges to "the sensible" identify how people's experience of the everyday world gets reoriented, and the normalised forms of being and acting in the world are 
subverted, producing a "disruptive aesthetic" (Markussen 20II). What is encountered as an "activist" performance in public space becomes "art as dissensus" which then breeches "the boundaries between what is supposed to be normal and what is supposed to be subversive, between what is supposed to be active, and therefore political, and what is supposed to be passive or distant, and therefore apolitical (Rancière 2007, 267). The dissonance or uncertainty acts on the public's senses, perception, and subsequently their emotions and interpretations of their urban experience, or even arguably what activism can look or feel like. These actions disrupt existing paradigms of shared meaning (the distribution of the sensible, and values and then purposes new ones. It is this aesthetic dimension and intended affect of the performance and their insertion into cultural processes that they can contribute to a reimagining of urban life. One more example of such a redistribution for Extinction Rebellion comes with its projection and performance; we can now all imagine a different type of performance as disruption and a different way idea can be communicated in public space, an alternative to cooperate ownership and marketing in public space. Eliciting Rancière helps to broaden the scope to reception; an approach might provide a productive reordering of how we engage in these types of performative protests and their reception in urban contexts. Indeed, their potential may rest in symbolic realm, but can still have an affective response. The encounters might produce unfamiliar, disorienting and unregulated. Ultimately, they disrupt our sense of the contemporary world, our understanding of what can happen in public space, who and what can be highlighted in that space, and what can be said in that space. The political potential of performative activism remains in their capacity to engage the general public and to generate broader political and social transformations. Here, the protest creates an "disruptive aesthetic" that eludes the regimentation of life and work promulgated by corporate capital and its instrumentalization of human creativity. The works discussed demonstrate that urban public space can have a multitude of functions and is indeed far more flexible and fluid than otherwise conceived; and more, that it is a living and creative space that expands the possibilities of experience through the participatory practices of all participants (Coombs and O'Connor, 20l I). Rancière describes this as "establishing an element of interdeterminacy in the relationship between artistic production and political subjectivity" (2007, 257).

\section{Conclusion}

The visuals and corporeal experience contribute to a cacophony that engages our interest, seduces our feelings, produces our reality and demands responsibility in action (Aulich in McGarry et al., 2020, 27I). These disruptions resist typical definitions of public art and subsequently typical notions of social and political engagement. These performative activisms are collective in nature; that is, they context and outcomes are produced together with audiences or publics. They forge the way towards these new cultural forms in a world that needs innovative ways to encourage institutions, people and communities to challenge the inequities presented to them, and experience something different. The interactions with the activists and/or the mediating objects can shape our perceptions and encourage psychological self-determination at a time when many people feel powerless in the face of the growing political and environmental injustice enacted upon individuals and communities globally. 
There may be some blind spots to XR's visual communication and performances, but overall, they do elucidate how public space, democracy, and aesthetics interface with climate change on a collective level. Several different scholars' words can be instructive here to illustrate the power of collective action in the context of climate change aesthetics, and I mention only a few here. Philosopher Jodi Dean sees the "crowd" in this context group of performative protestors, as a new way of thinking against individualist or leader lead politics, but as a collective state and that such momentary equality might unleash, "the basis for a new political composition" $(2016,25)$. Yet, as a cautionary warning to this political efficacy, she reminds us that "dominant power always allows for the carnivalesque" (2016, 158). Anthropologist Arjun Appadurai sees the imagination as a "collective practice"; the future can only be formed together $(2013$, 87). Appadurai's "ethics of possibility," finds "thinking, feeling, and acting increase the horizon of hope, that expand the field of the imagination, that produce greater equity in what I have called the capacity to aspire, and that widen the field of informed, creative, and critical citizenship" $(2013,295)$. Giles Deleuze's 'fold' (1988; 1993) also comes to mind: the folding of the interior to exterior world. The art and activist experience does not transport the public away from the world but reworks the stuff of the world, producing new combinations, new ways of folding the world "into" the self, making space for new subjectivities to emerge and action to take place.

\section{References}

Appadurai, A. (2013) The Future as Cultural Fact: Essays on the Global Condition. London: Verso Books.

Aulich, J. (2020) "Conclusion: Reflections on Protest and Political Transformation since I789" in McGarry, A., I. Erhart, H. Eslen-Ziya, O.Jenzen, U. Korkut (eds), The Aesthetics of Global Protest: Visual Culture and Communication. Amsterdam: Amsterdam University Press.

Barad, K. (2007) Meeting the Universe Halfway: Quantum Physics and the Entanglement of Matter and Meaning. Durham, NC: Duke University Press.

Barad, K. (2010) "Quantum Entanglements and Hauntological Relations of Inheritance: Dis/continuities, SpaceTime Enfoldings, and Justice-to-Come," Derrida Today, 3(2): Pp. 240-268.

Butler, J. (2015) Notes toward a Performative Theory of Assembly. Cambridge, MA: Harvard University Press.

Coombs, G. (2014) "Activism, art and social practice: a case study using Jacques Ranciere's framework for analysis." Proceedings to the Art Association of Australia and New Zealand's Annual Conference.

Coombs, G. and O'Connor, J. (20II) "Come together: Forging publics in Brisbane's Gallery of Modern Art," Art \& The Public Sphere, I (2). PP I39-I57.

Dean, J. (2016) Crowds and Party. New York and London: Verso.

Demos, T.J. (2020) “Extinction Rebellions.” Afterimage, Vol. 47, Number 2, pp. 14-20. 
Douglas, M. (20II). "Situating social contingency: mobility and socially engaged pubic art." In Urban Interior: informational explorations, interventions and occupations. Ed. Rochus Urban Hinkel. Germany: Spurbuchverlag. pp. 45-2007.

Duncombe, S. (2018) "An Age of Protest, Protest For the Age.” In Rogger, Basil, Voegeli, Jonas, Widmer, Ruedi, Museum Für Gestaltung Zürich, Editor, Host Institution, and Zürcher Hochschule Der Künste. 20I8. Protest: The Aesthetics of Resistance. Zurich: Lars Müller Publishers.

Extinction Rebellion. N.d. Demands. https://extinctionrebellion.uk/the-truth/demands/. Accessed 13 July 2020.

Heardman, P. (2019) "The meaning behind Extinction Rebellion's red-robed protesters.” Dazed. https://www.dazeddigital.com/politics/article/44238/I/meaningbehind-extinction-rebellions-red-robed-protesters-london-climate-change. Accessed 2 July 2020.

Kraidy, M. M. (2016) The Naked Blogger of Cairo: Creative Insurgency in the Arab World . Cambridge, MA: Harvard University Press.

Kraidy, M. M. (2017) "Biopolitical and Phenomenological Underpinnings of Embodied Contestation: Further Reflections on Creative Insurgence." In Global Cultures of Contestation : Mobility, Sustainability, Aesthetics and Connectivity, edited by Esther Peeren, et al., London: Palgrave Macmillan.

Machin, D. and Polzer, L. (20I5) Visual Journalism. London: Palgrave Macmillan.

Markussen, T. (20II) "The Disruptive Aesthetics of Design Activism: Enacting Design between Art and Politics." Nordic Design Research Conference: Helsinki. http://www.nordes.org/opj/index.php/n I 3/article/viewFile/I 02/86. Accessed I6 July 2020. 
It's (Red) Hot Outside!

McGarry, A. (2019) Crack Magazine, 107.

McGarry, A., I. Erhart, H. Eslen-Ziya, O.Jenzen, U. Korkut (eds.) (2020) "Introduction.” In The Aesthetics of Global Protest: Visual Culture and Communication. Amsterdam: Amsterdam University Press.

Mirzoeff, N. (2015) How to See the World. London: Pelican Books.

Morgan, G. (2019) "How Extinction Rebellion's graphics became the symbol of environmental uprising." New Stateman. Accessed I5 July 2020.

https://www.newstatesman.com/politics/environment/2019/09/how-extinction-rebellionsgraphics-became-symbol-environmental-uprising

Morris, K. (2019) "The Defiant Art and Design of Extinction Rebellion.” Frieze. https://frieze.com/article/defiant-art-and-design-extinction-rebellion. Accessed 3 July 2020.

Olcese, C. and Savage, M. (2015) 'Notes towards a 'social aesthetic': Guest Editors' introduction to the special section". The British Journal of Sociology, Vol: 66 Issue 4.

Peeren, E.,Celikates, R.,de Kloet, J.,Poell, Th. (eds.) (2017) Global Cultures of Contestation: Mobility, Sustainability, Aesthetics and Connectivity. London: Palgrave Macmillan.

Rancière, J. (2006) The Politics of Aesthetics: The Distribution of the Sensible, London: Continuum.

Rancière, J. (2007) “Art of the Possible," Artforum 45: pp. 256-268.

Rogger, B., Voegeli, J., Widmer, R., Museum Für Gestaltung Zürich and Zürcher Hochschule Der Künste (2018) Protest: The Aesthetics of Resistance. Zurich: Lars Müller Publishers.

Shiels, J. (2019) "Extinction rebellion: How to Craft a Protest Brand." https://theconversation.com/extinction-rebellion-how-to-craft-a-protest-brandI23084. Accessed 10 July 2020.

Taussig, M. (2012) "I'm so Angry I Made a Sign” Critical Inquiry. Vol. 39, No. I, pp. 56-88.

I36 | The Journal of Public Space, 5(4), 2020 | ISSN 2206-9658

City Space Architecture / UN-Habitat 